\title{
Posthatching Development of Synapses in the Neuropil of Nucleus Rotundus of the Zebra Finch: A Quantitative Electron Microscopic Study
}

\author{
BARBARA NIXDORF AND HANS-JOACHIM BISCHOF \\ Universität Bielefeld, Fakultät für Biologie, Lehrstuhl für Verhaltensphysiologie, \\ Morgenbreede 45, Postfach 8640, 48 Bielefeld 1, Federal Republic of Germany
}

\begin{abstract}
The development and maturation of synapses in the nucleus rotundus of the zebra finch were examined at $1,5,10,20$, and 100 days posthatching. Quantitative ultrastructural techniques were applied to investigate synaptic density, size of presynaptic terminals, and length of postsynaptic thickenings. During development there is a steady increase in the number of synapses and an enlargement of the presynaptic terminals. The length of the postsynaptic thickenings, however, decreases significantly during posthatching development. All three parameters reach adult values within 20 days of age. A close relationship was found between the enlargement of the presynaptic terminals and the increase in the number of contact zones up to the 20th day. The general feature of this developmental progress is in good agreement with biochemical and, to a certain extent, behavioral studies.
\end{abstract}

Key words: visual system, birds, posthatching development, quantitative analysis

The general pattern of the development of synapses in the visual system of vertebrates has been investigated in various mammalian species (Cragg, '72, '75; Lund and Lund, '72; Vrensen and DeGroot, '73, '77; Mathers et al., '78; Dyson and Jones, '80, '84; O'Kusky and Colonnier, '82; Winfield ' 81 , '83; Bähr and Wolff, '85). From a comparative point of view, it is of special interest whether similar developmental processes occur in the other homoiothermic class of vertebrates, the birds. To date, very little is known about synapse formation and maturation of synaptic profiles in these animals.

As most of the mammalian studies were done on altricial animals like rats, cats, and rabbits, it seemed most promising, for the sake of comparison, to choose an altricial bird for our study. Zebra finches, which hatch in a rather underdeveloped state and with closed eyes, may be described as altricial. The eyelids develop progressively and usually open between 5 and 7 days posthatching. From the tenth day on zebra finches can fix their eyes on objects, and from the 15th day on they can distinguish between a dummy and their parents (Bischof and Lassek, '85). Around day 20 they are just fledged and therefore have to perform many behavioral acts that are strongly dependent on a fully developed visual system. The general development of the vi- sual system of the birds parallels behavioral development (Bischof and Herrmann, '84; Herrmann and Bischof, '86).

This report concerns the normal course of posthatching development in the nucleus rotundus of the zebra finch. In birds, the nucleus rotundus is the prominent thalamic relay station of the tectofugal pathway (Karten and Hodos, '70; Benowitz and Karten, '76; Nixdorf and Bischof, '82; Watanabe et al., 85). The nucleus rotundus is easy to detect at any age posthatching, making it particularly suitable for studies of synaptic development. We investigated synapses in the neuropil of the nucleus rotundus during different stages of development and searched for morphological correlates at the ultrastructural level. A quantitative analysis was carried out on synaptic density, presynaptic terminal size, and the length of the postsynaptic thickening, also called postsynaptic density (PSD).

\section{MATERIALS AND METHODS}

Fourteen zebra finches of both sexes taken from the institute's stock, aged 1, 5, 10, 20, and 100 days, were used for

Accepted March 6, 1986. 
this study. A total of 1,014 synaptic contacts in an area of $11,247 \mu \mathrm{m}^{2}$ were counted by using thin sections and were measured on a graphics tablet (Digikon) connected to a microcomputer (Digital Equipment, PDP 11). At least two birds of each age group and a minimum of 20 electron micrographs were available for testing the pooled data for significance by the Mann-Whitney U-test. No more than two blocks of the same nucleus were used for quantitative analysis.

\section{Tissue preparation}

The birds were deeply anesthetised and perfused via the left ventricle with $0.1 \mathrm{M}$ sodium cacodylate buffer followed by a mixture of $3 \%$ paraformaldehyde and $3 \%$ glutaraldehyde in the same buffer (Karnovsky, '65). The brains were exposed, and after immersion in the fixative overnight, they were sectioned at $100 \mu \mathrm{m}$ with the aid of an Oxford vibratome. Tissue pieces were collected from the rostral, medial, and caudal $\mathrm{n}$. rotundus. In this study only samples from the medial part were used. For better identification in the electron microscope, all tissue samples were dissected with a vertex in the dorsomedial border outside the rotundus region. The tissue pieces were washed in $0.1 \mathrm{M}$ sodium cacodylate buffer and postfixed in $1 \% \mathrm{OsO}_{4}$ solution for 2 hours at $4^{\circ} \mathrm{C}$. Following a $2 \times 15$-minute buffer wash, the tissue was dehydrated in a graded series of methanol and embedded in Epon 812. The ultrathin sections were double stained with ethanolic uranyl acetate $(2 \%)$ and with concentrated lead citrate (Dawes, '81). These samples were examined in a Hitachi 500 electron microscope.

\section{Orientation in the electron microscope}

Semithin sections $(\mathbf{1} \mu \mathrm{m})$ were cut from the Epon blocks and stained with toluidine blue. The outline of one representative section from each block and the border of the $n$. rotundus were drawn by using a drawing tube attached to a Zeiss light microscope. At the same magnification the bars of a 300-mesh grid were drawn onto a transparency. In order to locate a particular region of an ultrathin section in the electron microscope, the transparency was positioned on the outline drawing according to the image displayed in scan position, thus providing a coordinate system. For this procedure it is essential that the ultrathin sections be mounted exactly parallel to the grid bars.

\section{Data analysis}

Electron micrographs were systematically taken from the center of the medial $n$. rotundus at a primary magnification of 7,000 and enlarged photographically to give a final magnification of 24,000 . Photographs were taken exclusively of the neuropil; somata, capillaries, and myelinated axons were ignored. The criteria adopted for identification of a synapse were as follows: membrane appositions between two neuronal structures with a recognizable density along or near the membrane apposition area and vesicles accumulated near the presynaptic membrane (Fig. 1).

The membranous synaptic density was found on both the pre- and postsynaptic membranes (Colonnier '68). Synapses were only counted if the presynaptic terminal and the paramembranous specialization were completely visible in the micrograph. The vesicles associated with synapses were spheroidal or pleomorphic. Synapses with flattened vesicles were rarely observed. No attempt was made to classify synapses with respect to their vesicle type. All synapses identified according to the criteria described above were marked on the micrographs used for final measurements.

The sizes of presynaptic terminals, i.e., area of axon endings in cross section ( $\mathrm{At}_{1}, \mathrm{Fig} .1$ ), and the lengths of postsynaptic thickenings (PSDs) were determined with the help of a graphics tablet (Digikon) that was linked to a PDP 11. Profile size-frequency histograms of presynaptic terminals and the distribution of the length of the PSDs were plotted for each bird, indicating a nonnormal distribution of presynaptic terminal size and PSDs (see Fig. 2).

Therefore, we used the nonparametric Mann-Whitney Utest for statistical analysis. The U-test is sensitive to differences of the median values, less sensitive to different skewness, and not affected by variation of the variance. The same procedure of measuring presynaptic terminals was used in each age group except for 1-day-old zebra finches, in which presynaptic terminals were not yet well estab-

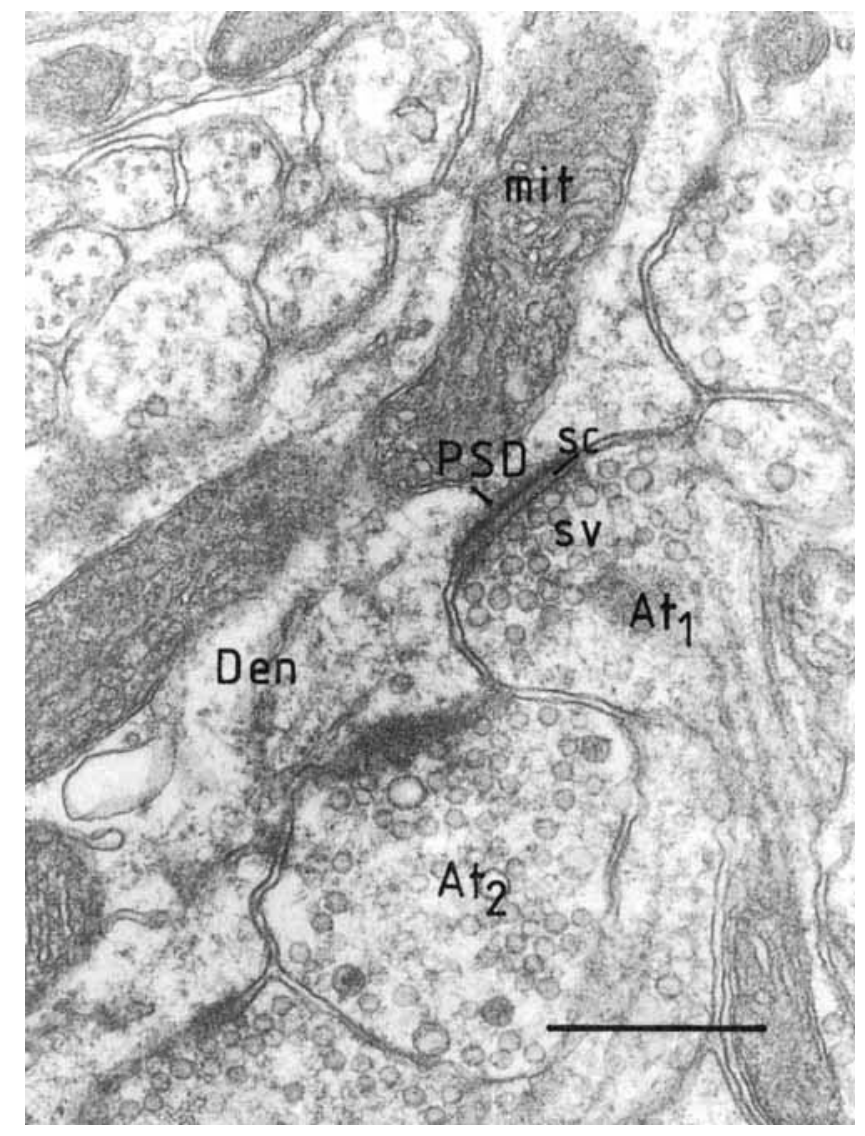

Fig. 1. Electron micrograph illustrating a typical synapse in the neuropil of $n$. rotundus of the adult zebra finch. The postsynaptic structure is a dendrite cut in its longitudinal plane. The presynaptic terminal (At1) is characterized by synaptic vesicles that accumulate near the synaptic apposition zones. The average diameter of synaptic vesicles is $35.40 \mathrm{~nm}$. The synaptic cleft (sc) between pre- and postsynaptic structure is clearly visible. The postsynaptic-membrane-associated density (PSD) is more prominent than the presynaptic density. The length of the PSDs and the cross-sectional area of the presynaptic terminals were measured. In this plane of section the axon terminal At2 is cut obliquely, resulting in a fuzzy appearance of the membranes. Therefore, this synapse would not be admitted for synapse measurements. At, axon terminal; Den, dendrite; mit, mitochondria; PSD, postsynaptic thickening; sc, synaptic cleft; sv, synaptic vesicles. Bar $=0.5$ $\mu \mathrm{m}$. 

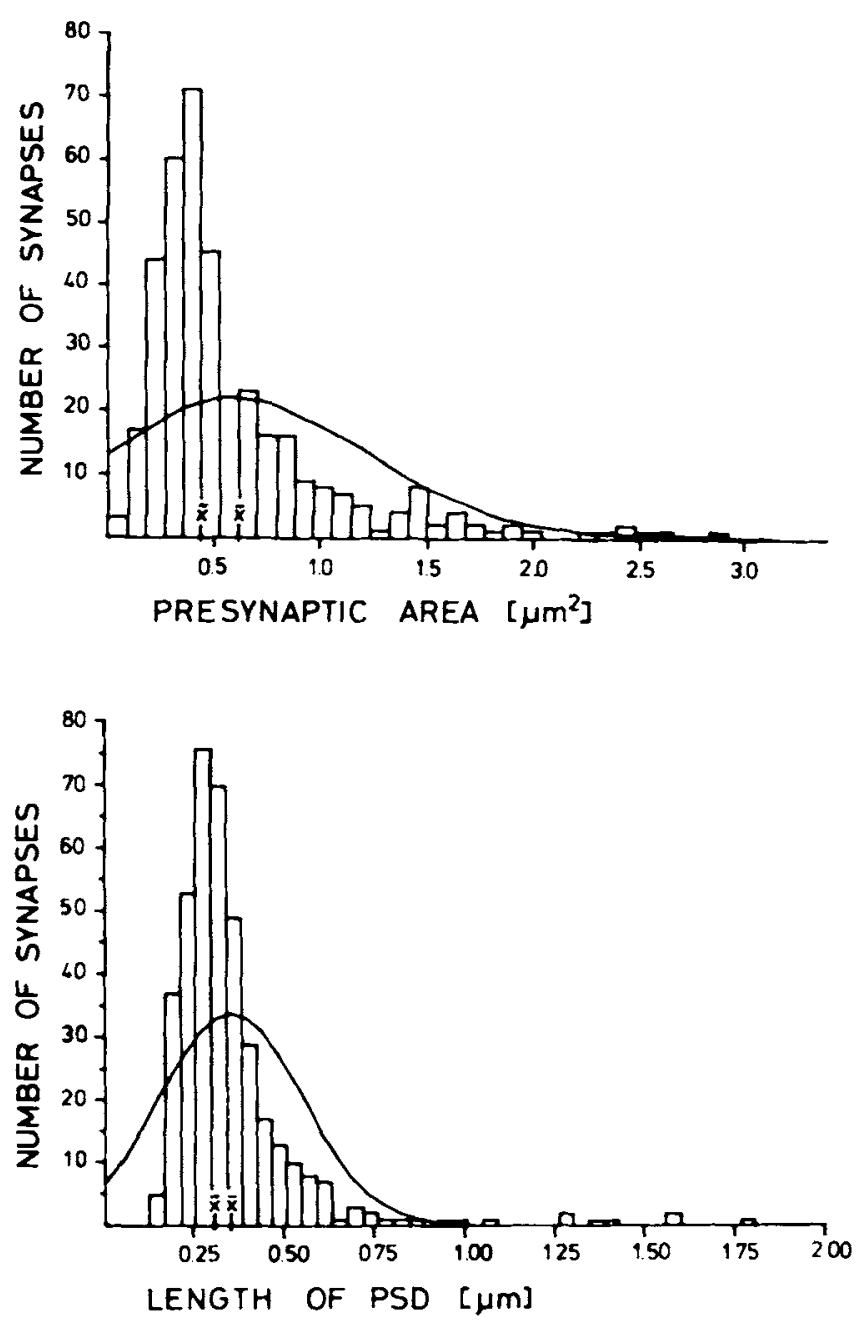

Fig. 2. Frequency distribution of two parameters of synapses in the neuropil of nucleus rotundus of an adult zebra finch. Top: Histogram showing the cross-sectional areas of 381 terminals. The median $(\widetilde{\mathbf{x}})$ is $0.436 \mu \mathrm{m}^{2}$, and the average terminal size $(\bar{x})$ is $0.624 \mu \mathrm{m}^{2}$. Bottom: Histogram showing the distribution of the length of the postsynaptic thickening (PSDs) of 393 synaptic contact zones. The median $(\widetilde{\mathrm{x}})$ is $309 \mathrm{~nm}$, the mean $(\widetilde{\mathrm{x}})$ is $355 \mathrm{~nm}$. Curves overlying the data are the corresponding normal distributions. These curves indicate that the normal distribution might not be an adequate approximation for the frequency distributions.

lished. In this age group only the area covered by presynaptic vesicles was traced. Therefore, the values in this age group might be slightly underestimated.

\section{RESULTS \\ Density of synapses}

In 1-day-old zebra finches, the nucleus rotundus has developed to the stage at which its boundaries can easily be determined. Although synaptic contacts are sparse, numerous membrane appositions are observed that are similar to normal synapses in every respect, except that they lacked vesicles. According to our definition of a synapse, only those containing vesicles have been used for data analysis. Synaptic density represents the actual number of synapses observed in a given areas of tissue. The values reflect the relative density and are not corrected for possible sampling errors due to variation in size of synapses.

In Figure 3 the density of synapses is displayed as a function of age. A steady increase of synaptic density was observed up to the age of 20 days, at which age adult values are reached. The mean and median of the frequency distribution of the number of synapses do not differ within each age group. Therefore a Gaussian distribution of synapses can be expected in the investigated area. Differences in synaptic densities were tested with the two-tailed t-test. The increase in number of synapses up to day 20 proves to be significant $(\mathrm{P}<.001)$.

In 1-day-old zebra finches, the synaptic density is found to be 41 synapses/ $1,000 \mu \mathrm{m}^{2}$ ( $28 \%$ of the adult value). AIthough the eyes of zebra finches are still closed during the first 5 days posthatch, there is a $13 \%$ increase $(P<.001)$ in the number of synapses per $1,000 \mu \mathrm{m}^{2}$, reaching $41 \%$ of the adult value. At the age of 10 days, when the eyes of zebra finches are finally open, synaptic contact zones have more than doubled in number since hatching. At the age of 20 days, synaptic density has reached the adult level of 140 symapses per $1,000 \mu \mathrm{m}^{2}$, and no further significant change was found between the two age groups (20 vs. 100 days: $P$ $>$.4).

\section{Size of presynaptic terminals}

During development the size of presynaptic terminals in the neuropil of the nucleus rotundus increases progressively from $0.197 \mu \mathrm{m}^{2}$ in 1-day-old zebra finches to 0.436 $\mu \mathrm{m}^{2}$ in the adult (Fig. 4). Size, as used in this context, always describes the median value of the presynaptic area evaluated from the pooled data of each age group. No correction factors were applied since the relative values are sufficient to show the developmental trends.

In the first 5 days posthatch, the median value of the presynaptic area expands by $20 \%$, reaching $65 \%$ of the adult size. The observed enlargement is highly significant

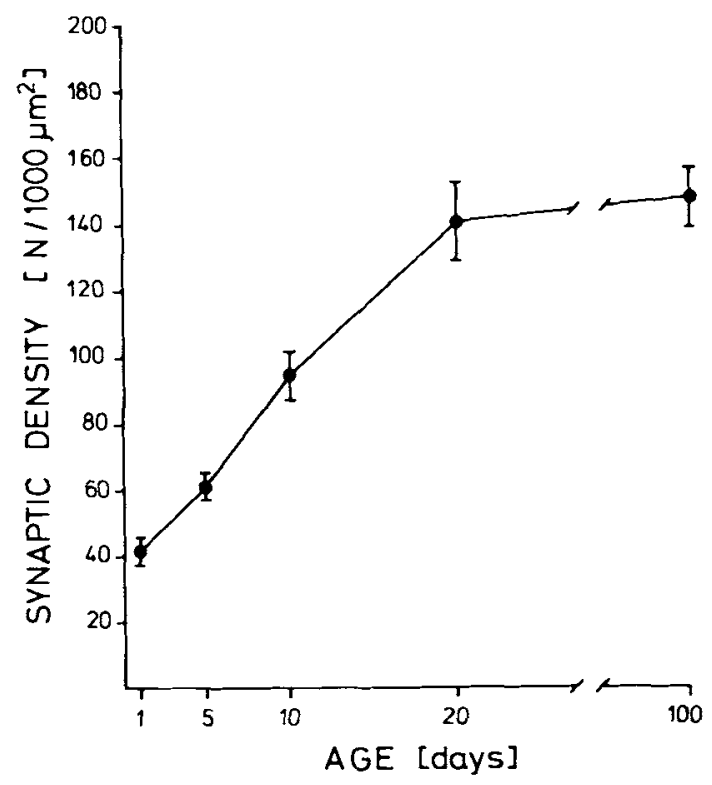

Fig. 3. The development of synaptic density per $1,000 \mu \mathrm{m}^{2}$ in the neuropil of $n$. rotundus. The bars represent the median and the standard deviation of the median. 


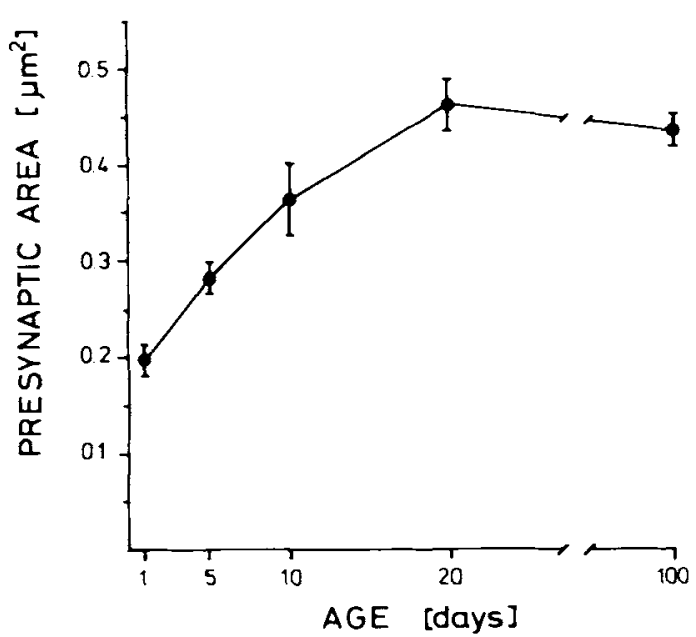

Fig. 4. The development of the size of the presynaptic area from hatch to adulthood (100 days). The bars represent the median and the standard deviation of the median.

$(\mathrm{P}<.001)$. Between day 5 and day 10 the terminal expands by another $20 \%(\mathrm{P}<.01)$, reaching $84 \%$ of adult size. At the age of 20 days a $6 \%$ "overshoot" of synaptic terminal size is observed, but this is not significant compared with terminal sizes of adult zebra finches. The $20 \%$ increase from day 10 to day 20 , however, is significant $(\mathrm{P}<.04)$. During these 10 days the median value of synaptic terminals increases by $0.1 \mu \mathrm{m}^{2}$.

In addition to investigating the development of presynaptic terminal size, we also determined the percentage of total presynaptic area included in the electron micrographs. In 1-day-old zebra finches, $1 \%$ of the neuropil of nucleus rotundus is occupied by presynaptic terminals. At the age of 5 days, the total presynaptic area amounted to about $2.4 \%$, increasing to $4.4 \%$ at the age of 10 days. This trend continues, reaching $7.7 \%$ in 20 -day-old zebra finches and $9.1 \%$ in adults. It is emphasized that only presynaptic profiles with synaptic vesicles and clearly defined membranous structures have been identified as those forming synapses. Therefore the calculation of percentage is an underestimation of the real values, for, in older animals ( $>5$ days), there are always large numbers of vesicle-filled structures lacking membrane specializations. In these instances the synaptic junctions are probably not included in the plane of section.

Although the median values of presynaptic terminal size do not increase from day 20 on, there still seems to be a small increase of the space occupied by presynaptic terminals up to adulthood. Assuming that the maximal number of presynaptic terminals in the neuropil of $\mathbf{n}$. rotundus is reached by 100 days, the dynamics of presynaptic terminals occupying available space can be described as follows: The largest increase in space occupied by presynaptic terminals is detected between day 1 and day 5 with an increment of $144 \%$ (36\% per day). Between day 5 and day 10 there is another $85 \%$ increase (17\% per day), slowing down to $75 \%$ in the next 10 days ( $7.5 \%$ per day). Compared to this rapid development only a negligible percentage $(18 \% ; 0.2 \%$ per day) is added to the already available presynaptic terminals between 20 and 100 days.
A comparison of the development of presynaptic terminals and of synaptic density indicates a positive correlation. The relation of the two parameters is shown in Figure 5, in which a linear regression has been applied for the median values of each age group (correlation coefficient .976). When a linear regression is applied to the median of each individual, the correlation factor is somewhat smaller $(0.882)$ be cause of the larger variance of the data. However, it is still a linear correlation.

\section{Length of postsynaptic thickening}

Figure 6 shows the length of the postsynaptic thickening (PSD) in the five age groups. Its median value decreases by $14 \%(\mathbf{P}<.001)$ during development from the age of 1 day $(361 \mathrm{~nm})$ to adult age $(309 \mathrm{~nm})$. By the age of 20 days, the PSD is reduced by $16 \%(\mathrm{P}<.001)$. Although the median lengths of PSDs of any two neighboring age groups do not differ significantly, there is a significant difference between the adult age group and the age groups younger than 20 days ( 10 days: $\mathrm{P}<.01 ; 5$ days: $\mathrm{P}<.001 ; 1$ day: $\mathrm{P}<.001$ ).

Thus, by pooling the data for 1-, 5-, and 10-day-old birds and those of 20 and 100 days, respectively, a significant reduction in the length of the postsynaptic density can be demonstrated. $(\mathrm{P}<.01)$.

\section{DISCUSSION}

Maturation of synapses has been studied in the visual cortex of cats (Cragg, '72, '75; Winfield, '81, '83), rats (Dyson and Jones, '80, '84; Blue and Parnavelas, '83; Bähr and Wolff, '85), monkeys (O'Kusky and Colonnier, '82), and rabbits (Vrensen and DeGroot, '73; Vrensen et al., '80; DeGroot and Vrensen, '78; Mathers et al., '78; Müller et al., '81). Therefore, comparative data are available that allow common features of synapse development or diverse trends in the developing visual system of mammals and birds to be detected. Furthermore, ultrastructural analysis of the superior colliculus of the rat (Lund and Lund, '72), monkey (Holstein et al., '85), and rabbit (Vrensen and DeGroot, '77; Vrensen et al., '80; Mathers et al., '78) as well as studies on

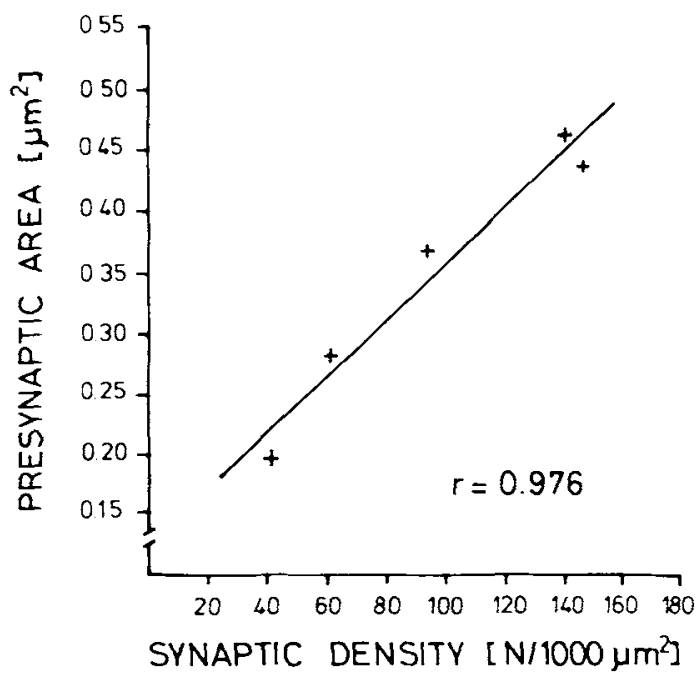

Fig. 5. Relationship between the size of presynaptic terminals and number of synapses in the neuropil of $n$. rotundus during postnatal development. The correlation function is $\mathrm{y}=0.002 \mathrm{x}+0.129$. 


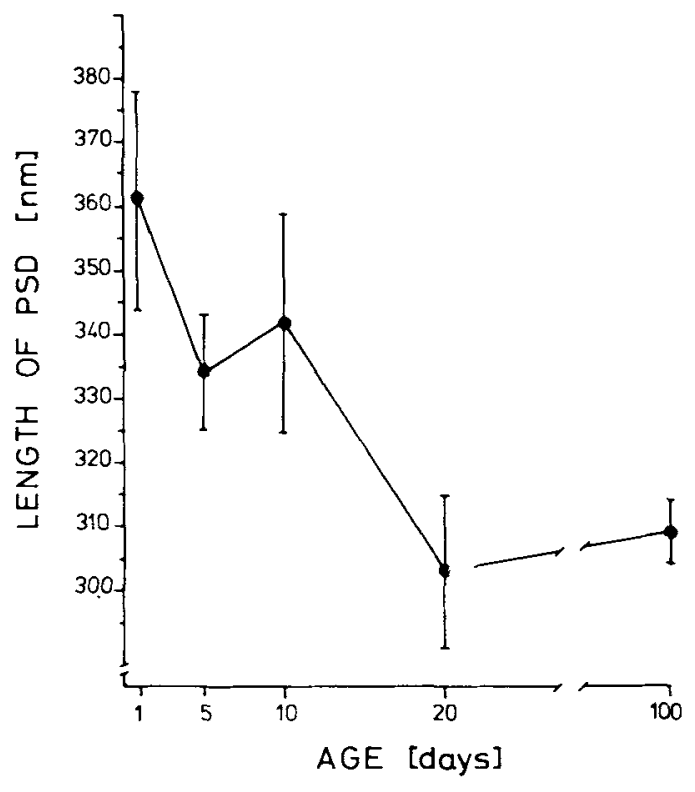

Fig. 6. Postnatal changes in the length of the postsynaptic apposition zone (PSD). The bars represent the median and the standard deviation of the median.

the development of the nucleus geniculatum lateralis (LGN), the thalamic relay station to the visual cortex in mammals, provide additional data for comparative studies at the ultrastructural level. With respect to the increase of synaptic density per unit area and the enlargement of presynaptic profiles per surface area, the observed developmental processes in the neuropil of the nucleus rotundus in zebra finches are in good agreement with most of the abovecited literature. However, we have found a significant reduction of the median length of the postsynaptic thickening (PSD) between hatch and adulthood. To our knowledge this is the first time that changes in the length of PSDs during development have been reported. It is not clear, however, whether this is a real interspecies difference or the consequence of the nonparametric test procedure we used (see "PSD"-Discussion).

\section{Density of synapses}

The rapid increase of synaptic density demonstrated in the nucleus rotundus of the zebra finch is likely to be a general feature of developing neuronal tissue, and one which occurs as soon as neuronal circuitry is established (Aghajanian and Bloom, '67). In contrast to the relatively stable value for the number of synapses in the zebra finch between the 20th day posthatch and adulthood, the synaptic density in the visual cortex of cats declines until adulthood, thus indicating an initial overshoot in the number of synapses (Cragg, '75). In general, overshoot and reduction of synaptic density during developmental processes is discussed in the literature. A series of studies demonstrate a decrease of synaptic density after reaching a peak some time after birth. This can be demonstrated for area 17 of the macaque (O'Kusky and Colonnier, '82), for the LGN of the same species (Holstein et al., '85), and for the visual cortex of rabbits (Mathers et al., '78; but see Vrensen, '78) and cats (Cragg, '75). Cragg ('75), however, emphasized that the overshoot of synapse number in the visual cortex of the cat, as mentioned earlier, is most likely not a true redundancy but rather a "dilution effect" caused by the fact that cortical volume is still increasing (Vrensen, '78). Dyson and Jones ('80) reported that the density of synaptic junctions in the visual cortex of the rat remains relatively constant after a rapid increase between posthatch days 15 and 28 . In the superior colliculus of the same species (Lund and Lund, '72) and in the superior colliculus of the rabbit (Mathers et al., '78), no reduction in synapse number during development has been detected. Similarly, our results concerning the development of synaptic density in the nucleus rotundus of the zebra finch do not indicate an overshoot of synaptic density.

The density of synapses might to some extent represent the completeness of the wiring diagram of the neuronal circuitry. In the zebra finch there is a $49 \%$ ( $12 \%$ per day) increase of synapse number per $1,000 \mu \mathrm{m}^{2}$ during the first 5 days posthatch prior to eye opening. The maturation of the wiring diagram therefore starts before there is visual input. A similar effect is reported for the visual cortex of the rabbit (Vrensen, '78). The development of synapse proliferation in the $n$. rotundus of zebra finches seems to be more or less independent of external stimuli, since the onset of visual input (day 5 to day 10) does not accelerate the increase in synaptic density. However, recent experiments from our research group demonstrate that the number of synapses can be essentially altered by visual deprivation (Nixdorf and Bischof, in preparation).

At the age of 20 days posthatch, neuronal circuitry seems to be almost complete, since synaptic density exhibits no further change until adulthood. This is supported by biochemical studies in which the amount of gangliosides have been measured in the zebra finch brain (Seybold and Rahmann, ' 85 ). There is evidence that the ganglioside fraction GD1a plays an important role in synaptogenesis. In the zebra finch brain, this ganglioside was found to increase from $4 \%$ of total ganglioside at hatch to $16.5 \%$ on day 18 . After 18 days the phase of increase in GD1a is completed and the ganglioside level remains relatively constant during further development.

Although synaptic density indicates the completeness of the wiring diagram, changes in number of synapses might not be a simple cumulative process. In the developing neuronal tissue different types of synapses might develop at different stages with different dynamic processes (Winfield, '81, '83; Albanese et al., '83; Dyson and Jones, '80, '84). Furthermore, synapse splitting and elimination might also be involved (Innocenti et al., '77; Carlin and Siekevitz, '83; Siekevitz, '85; Dyson and Jones, '84; Holstein et al., '85). We neglected these phenomena in our study, since, as a first step, we wanted to examine the gross developmental process.

\section{Presynaptic terminal size}

Additional information about the dynamics of the establishing neuronal circuitry can be obtained from various ultrastructural characteristics of synapses. In particular, the changes in the pre- and postsynaptic appositional membranes, changes in the size and shape of the presynaptic terminals, and changes in the number and types of synaptic vesicles indicate the development of the neuronal circuitry. Our results indicate a steady enlargement of the presynaptic area during maturation. These data are in good agreement with findings in the occipital cortex of rats (Dyson 
and Jones,' 80 ), where an overall increase of $80 \%$ in the size of the presynaptic terminal was observed. To our knowledge, no other developmental studies on the visual system concerning this synaptic feature are to be found in the literature. Deprivation studies, however, show that the presynaptic terminal size is affected by alterations of the input to a brain area. In the visual cortex of deprived cats, Tieman ('84) observed a reduction in the size of axon terminal forming geniculocortical synapses by $25 \%$ as compared to synapses in nondeprived cats. In the $n$. rotundus of monocularly deprived zebra finches a similar effect can be detected. Synapses of the deprived n. rotundus have smaller (18\%) presynaptic terminals than those of the control side (Nixdorf and Bischof, in preparation). Therefore enlargement of presynaptic terminals seems to be, at least partly, an effect of environmental stimulation.

\section{Length of postsynaptic thickening}

Another characteristic feature of synapse maturation is displayed by the synaptic appositional membranes and their associated paramembranous specializations. In the zebra finch brain we have measured the length of the postsynaptic thickening (PSD) in osmicated tissue. Our results indicate a significant reduction of the median contact length during maturation. This is in contrast to measurements on synaptic length in the cortex of rabbits, monkeys, guinea pigs, and cats (Vrensen and DeGroot, '73; DeGroot and Vrensen, '78; O'Kusky and Colonnier, '82; Jones et al., '74; Cragg, '75), where no changes in the length of the postsynaptic apposition zone were detected during development. However, in all these animals only mean values of contact length were determined. Therefore, small changes in the size distribution of synaptic contact lengths (PSDs) might not have been detected. In our study we used the MannWhitney U-test for statistical analysis, since our PSD-his tograms indicate a nonnormal distribution of synaptic con tact length for all age groups.

Since the data that were previously available on devel oping PSDs were tested by the Student's t-test, where mean values are compared, we also applied the t-test to our data. Comparing the means rather than the medians of the PSDs from synapses in the $n$. rotundus of the zebra finch in different developmental stages has somewhat surprising effects: The mean values of PSDs fluctuate during development and no reduction in the length of PSDs is detected as shown in other species. We do not know whether the distribution of PSDs measured in other species was Gaussian, or, like in the zebra finch, nonnormal. Our calculation, how ever, indicates that these differences in statistical analysis might be a reason for the different results concerning the development of the length of synaptic apposition zones. We would like to mention that Güldner ('78) has shown PSD histograms that are very similar to those of the zebra finch. They did not apply statistics to their data because of the skewness of the frequency histograms. Mize and Horner ('84) also show very similar profile size frequency histograms of retinal terminals of the medial interlaminar nucleus (MIN) and of the ventral lateral geniculate nucleus (VLG). These authors compared the average values of their populations, although they do not mention the type of statistics they used.

The postsynaptic thickening (PSD) is a very plastic structure. It has been shown that under various experimental conditions the thickness of the postsynaptic membrane shows the tendency to increase with reduced sensory stimulation and vice versa (Rees et al., '84; Güldner and Phillips, '85). On the other hand, Vrensen and Nunes Cardozo ('81) have shown that synapses in the visual cortex have thicker postsynaptic apposition zones in visually trained rabbits compared with control animals. No change in the length of the PSDs was detected in those experiments.

Although the results of the different studies appear to conflict, the structural plasticity of the PSD seems to be confirmed. In the zebra finch brain the length of the PSDs decreases significantly during normal posthatch development, whereas in other species no change has been detected. The thickness of the PSD, which was not examined in this study, increases significantly during normal development as shown for the visual cortex of the rabbit (DeGroot and Vrensen, '78). It would be interesting to know if there are changes in the thickness of the PSDs from synapses of the n. rotundus or if the alterations of PSDs during development are restricted to changes of the length. At present this question is being investigated in our laboratory by using the ethanolic phosphotungstic acid (EPTA) technique.

\section{ACKNOWLEDGMENTS}

We are grateful to Mr. H. Stein for writing the computer program for nonparametric statistics and to Prof. Dr. Willimczik for providing the digital equipment. We would like to thank Prof. Dr. Jockusch for the use of the Oxford vibratome. We would also like to thank the anonymous referees for their very helpful comments. Mr. R. Church's improvement of the English is gratefully acknowledged. This work was supported by grants from the "Minister für Wissenschaft und Forschung des Landes Nordrhein-Westfalen" and from the Deutsche Forschungsgemeinschaft (Bi 245/ 2.3) to H.-J.B. and by the Studienstiftung des deutschen Volkes to B.N.

\section{LITERATURE CITED}

Aghajanian, G.K., and F.E. Bloom (1967) The formation of synaptic junctions in developing rat brain. A quantitative electron microscopic study. Brain Res. 6:716-727.

Albanese, A., E. Albanese, A. Brusco, and J.P. Saavedra (1983) A quantitative study of visual cortex synapses during the postnatal development of dark-reared rats. J. Neurobiol. 14:1-8.

Bähr, S., and J.R. Wolff (1985) Postnatal development of axosomatic synapses in the rat visual cortex: Morphogenesis and quantitative evaluation. J. Comp. Neurol. 233:405-420.

Benowitz, L.I., and H.J. Karten (1976) Organization of the tectofugal path way of the pigeon: A retrograde transport study. J. Comp. Neurol 167:503-520.

Bischof, H.-J., and K. Herrmann (1984) Ontogenetic development of sensory and song control areas in the zebra finch brain. Behav. Brain. Res. 12:171-172.

Bischof, H.-J., and R. Lassek (1985) The gaping reaction and the development of fear in young zebra finches (Taeniopygia guttata castanotis). $\mathrm{Z}$. Tierpsychol. 69:55-65.

Blue, M.E., and J.G. Parnavelas (1983) The formation and maturation of synapses in the visual cortex of the rat. II. Quantitative analysis. J. Neurocytol. 12:697-712.

Carlin, R.K., and P. Siekevitz (1983) Plasticity in the central nervous system: Do synapses divide? Proc. Natl. Acad. Sci. USA 80:3517-3521.

Colonnier, M. (1968) Synaptic patterns on different cell types in the different laminae of the cat visual cortex. An electron microscope study. Brain Res. 9:268-287.

Cragg, B.G. (1972) The development of synapses in the cat visual cortex. Invest. Ophthalmol. $11: 377-386$.

Cragg, B.G. (1975) The development of synapses in the visual system of the cat. J. Comp. Neurol. 160:147-166. 
Dawes, C.J. (1981) Biological Techniques for Transmission and Scanning Electron Microscopy. Ladd Research Industries, Inc, Burlington.

DeGroot, D., and G. Vrensen (1978) Postnatal development of synaptic contact zones in the visual cortex of rabbits. Brain Res. 147:362-369.

Dyson, S.E., and D.G. Jones (1980) Quantitation of terminal parameters and their interrelationships in maturing central synapses. Brain Res 183:43-59.

Dyson, S.E., and D.G. Jones (1984) Synaptic remodelling during development and maturation: Junction differentiation and splitting as a mech anism for modifying connectivity. Dev. Brain Res. 13:125-137.

Güldner, F.H. (1978) Synapses of optic nerve afferents in the rat suprachias matic nucleus. Cell Tissue Res. 194:37-54.

Güldner, F.-H., and S.C. Phillips (1985) Structural plasticity of developing optic synapses under different lighting conditions. Neurosci. Lett. $55: 225-228$.

Herrmann, K., and H.-J. Bischof (1986) Delayed development of song control nuclei in the zebra finch is related to behavioral development. J. Comp Neurol. 245:167-175.

Holstein, G.R., T. Pasik, P. Pasik, and J. Hamori (1985) Early postnatal development of the monkey visual system. II. Elimination of retinogen iculate synapses. Dev. Brain Res. 20:15-31.

Innocenti, G.M., L. Fiore, and R. Caminiti (1977) Early postnatal development of the callosal zone at the $17 / 18$ boundary in the cat. Acta Anat $99: 280$.

Jones, D.G., M.M. Dittmer, and L.C. Reading (1974) Synaptogenesis in guinea-pig cerebral cortex: A glutaraldehyde-PTA study. Brain Res. $70: 245-259$

Karnovsky, M.H. (1965) A formaldehyde-glutaraldehyde fixative of high osmolarity for use in electron microscopy. I. Cell Biol. 27:137A.

Karten, H.J., and W. Hodos (1970) Telencephalic projections of the nucleus rotundus in the pigeon (Columba livia). J. Comp. Neurol. 140:35-52.

Lund, R.D., and J.S. Lund (1972) Development of synaptic patterns in the superior colliculus of the rat. Brain Res. 42:1-20.

Mathers, L.H., Jr., K.L. Mercer, and P.E. Marshall (1978) Synaptic develop ment in the rabbit superior colliculus and visual cortex. Exp. Brain Res. 33:353-369.

Mize, R.R., and L.H. Horner (1984) Retinal synapses of the cat medial interlaminar nucleus and ventral lateral geniculate nucleus differ in size and synaptic organization. J. Comp. Neurol. 224:579-590.

Müller, L., A. Pattiselanno, and G. Vrensen (1981) The postnatal develop ment of the presynaptic grid in the visual cortex of rabbits and the effect of dark-rearing. Brain Res. 205:39-48.
Nixdorf, B.E., and H.-J Bischof (1982) Afferent connections of the ectostriatum and visual wulst in the zebra finch (Taeniopygia guttata castanotis Gould)-an HRP study. Brain Res. 248:9-17.

Nixdorf, B., and H.-J Bischof. Ultrastructural effects of monocular deprivation in the neuropil of nucleus rotundus in the zebra finch: A quantitative electron microscopic study. (in prep.)

O'Kusky, J., and M. Colonnier (1982) Postnatal changes in the number of neurons and synapses in the visual cortex (area 17) of the macacque monkey: A stereological analysis in normal and monocular deprived animals. J. Comp. Neurol. 210:291-306.

Rees, S., F.-H. Güldner, and L. Atkins (1985) Plasticity of synaptic structure: end bulbs of Held in the anterior ventral cochlear nucleus. Neurosci. Lett. [Suppl.] 15:56.

Seybold, U., and H. Rahmann (1985) Brain gangliosides in birds with different types of postnatal development (nidifugous and nidicolous type). Dev. Brain Res. 17:201-208

Siekevitz, P. (1985) The postsynaptic density: A possible role in long-lasting effects in the central nervous system. Proc. Natl. Acad. Sci. USA 82:3494-3498

Tieman, S.B. (1984) Effects of monocular deprivation on geniculocortical synapses in the cat. J. Comp. Neurol. 222:166-176.

Vrensen, G., and D. DeGroot (1973) Quantitative stereology of synapses: A critical investigation. Brain Res. 58:25-35.

Vrensen, G., and D. DeGroot (1977) Quantitative aspects of the synaptic organization of the superior colliculus in control and dark-reared rabbits. Brain Res. 134:417-428.

Vrensen, G. (1978) Ontogenesis of the visual cortex of rabbits and the effects of visual deprivation. Prog. Brain Res. 48:231-246.

Vrensen, G., J. Nunes Cardozo, L. Müller, and J. Van der Want (1980) The presynaptic grid: A new approach. Brain Res. 184:23-40.

Vrensen, G, and J. Nunes Cardozo (1981) Changes in size and shape of synaptic connections after visual training: An ultrastructural approach of synaptic plasticity. Brain Res. 218:79-97.

Watanabe, M., H. Ito, and M. Ikushima (1985) Cytoarchitecture and ultra structure of the avian ectostriatum: Afferent terminals from the dorsal telencephaion and some nuclei in the thalamus. J. Comp. Neurol. 236:241-257.

Winfield, D.A. (1981) The postnatal development of synapses in the visual cortex of the cat and the effects of eyelid suture. Brain Res. 206:166 171.

Winfield, D.A. (1983) The postnatal development of synapses in the different laminae of the visual cortex in the normal kitten and in kittens with eyelid suture. Dev. Brain Res. 9:155-169. 